\title{
Heat-transfer, inside of the ground heat-transfer units, from liquid, additionally cooling the oil- immersed transformer
}

\author{
Ilnur Madyshev ${ }^{1 *}$, Oksana Dmitrieva ${ }^{1}$, and Andrey Dmitriev ${ }^{2}$ \\ ${ }^{1}$ Kazan National Research Technological University, 420016 Kazan, Russia \\ ${ }^{2}$ Kazan State Power Engineering University, 420066 Kazan, Russia
}

\begin{abstract}
A device for cooling the oil-immersed transformer by means of thermoelectric transducers has been developed. Their operating principle is based on the fact that at night at minimum ambient temperature, the cold is accumulated inside of a vessel due to formation of water ice layer on the developed surfaces of thermoelectric transducers' ribs. Melting of this layer is used in the hottest time of a day for additional cooling of transformer oil in the cooling system of the transformer. Pre-cooling of the circulating water takes place in vertical ground heat-transfer units (VGHT units), mounted into ground drilled boreholes. Certain estimate calculations of the heat-transfer process have been carried out.
\end{abstract}

\section{Introduction}

Power oil-immersed transformers are essential elements of electrical engineering units and quality of distributed electrical power depends upon reliability and operating safety of these units [1]. One of the main factors, determining the reliability of transformers, is an efficient cooling of them. However, existing cooling systems do not always ensure a sufficiently effective heat removal from the winding insulation material at short-term significant overloads [2]. In this regard, relevant objective is the development of additional cooling system of transformers, capable of decreasing the peak load and its uniform distribution throughout operational period due to cold accumulation within hours of minimum heat load.

\section{Description of the cooling system}

An example of a constructive design of this system is application of additional vessel, equipped with a cascade of semiconductor thermoelectric modules (TEM cells), cold surfaces of which, generate the cold and are used for cooling the liquid in vessel, while hot surfaces are equipped with a system of heat discharge into the environment [3]. A coil pipe 7 is mounted into the lower part of oil-immersed transformer`s tank 1 for additional cooling of power transformer by liquid (water) from vessel 2. TEM cells 8 are fixed to the outer

${ }^{*}$ Corresponding author: ilnyr_91@mail.ru 
surface of one of the vessel walls 2. Hence, ribbing 9 has been executed from the side of TEM cells 8 in order to form the greatest thickness of ice layer on the inner surface of a vessel 2 (Fig. 1). A square or right angle shaped vertical channel 5 is installed for effective heat removal from heated sides of TEM cells 8 . Pre-cooling of the circulating water takes place in VGHT units 3 and 4, mounted into ground drilled boreholes of 10-100 $\mathrm{m}$ deep [4].

Additional cooling system of power oil-immersed transformers has two operation modes. The first operation mode - accumulation of cold - is used within operating hours of transformer, corresponding to small heat loads. By means of pump 6 with closed shut-off valves 11 , water from vessel 2 is supplied for a preliminary cooling into the first section of VGHT units 3. After that, the water enters a vertical channel 5, where heat removal from TEM cells' heated sur-faces 8 takes place. Liquid film, coming down along a vertical surface of a channel 5 most effectively removes the heat excess, providing lower temperature of the TEM cells ' cold sides 8 . Due to this, water crystallization and ice layer buildup take place on the inner ribbed surface of a vessel 2 . After that, water, heated in a vertical channel 5, is supplied for additional cooling into the second section of VGHT units 4 , and then enters the upper part of a vessel 2. Thus, the cold is accumulated inside of a vessel 2 at a constant circulation of cooling water due to the work of TEM cells 8 .

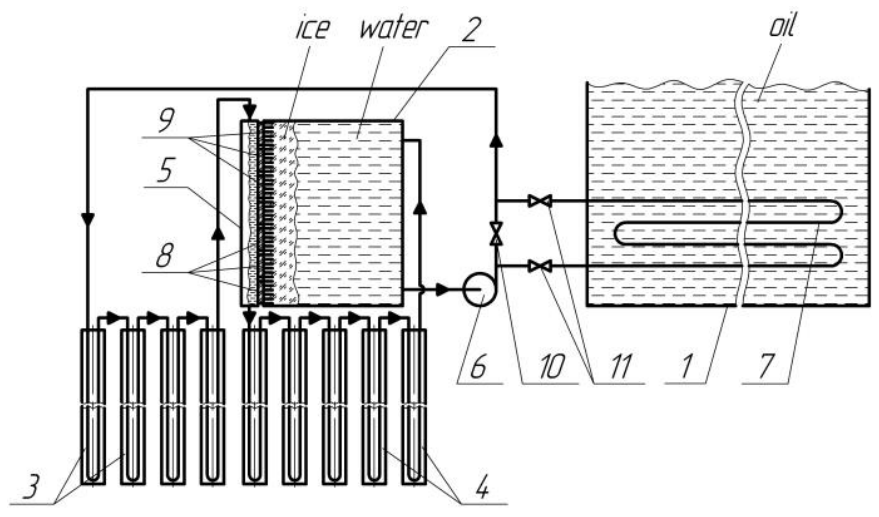

Fig. 1. Additional cooling system of power transformer: 1 - transformer tank; 2 - vessel; $3,4-$ VGHT units; 5 - square or right-angle shaped vertical channel; 6 - pump; 7 - coil pipe; 8 - TEM cells; 9 - ribs for ice layer formation; 10,11 - shut-off valves.

The second operation mode corresponds to high heat loads of the transformer operation, as a rule, at high ambient temperatures. In this case, by means of pump 6 with closed shutoff valves 10 , cooled water from vessel 2 is supplied into the coil pipe 7 and cools the transformer oil in the tank 1. After that, this water enters the same devices, as at the first operation mode. Thus, additional liquid cooling of tank's bottom part of transformer increases the efficiency of cooling the transformer oil within operating hours, corresponding to the greatest heat loads, preventing the failure of power transformers.

\section{Calculation procedure and results}

An arithmetic model, proposed in this study, is used for determination of design and operating mode parameters of VGHT units, designed for the water pre-cooling before its supply into vessel [5]. Heat transfer in the apparatus is described by the system of equations:

$$
Q=G_{m} c_{p}\left(t_{L 1}-t_{L 2}\right)=2 k_{l} \pi \operatorname{Ln}\left(t_{L}-t_{G}\right)
$$


where $Q$ - heat flow, W; $G_{m}$ - mass rate of heat-transfer agent (water), $\mathrm{kg} / \mathrm{s} ; c_{p}-$ mass specific heat capacity of water, $\mathrm{J} /(\mathrm{Kg} \cdot \mathrm{K}) ; t_{L 1}$ - water temperature at inlet of VGHT units, $\mathrm{K}$; $t_{L 2}$ - water temperature at outlet from VGHT units, $\mathrm{K} ; k_{l}$ - linear factor of heat transfer, $\mathrm{W} /(\mathrm{m} \cdot \mathrm{K}) ; L$ - length of VGHT units (borehole depth), $\mathrm{m} ; n$ - number of VGHT units; $t_{L}-$ average water temperature in VGHT units, $\mathrm{K} ; t_{G}$ - ground temperature, $\mathrm{K}$.

Linear factor of heat transfer, considering heat-transfer resistance of the filler layer of borehole, can be determined by the following formula:

$$
k_{l}=\frac{1}{\frac{1}{\alpha d_{1}}+\frac{1}{2 \lambda_{s}} \ln \frac{d_{2}}{d_{1}}+\frac{1}{2 \lambda_{z}} \ln \frac{d_{2}+2 \delta_{z}}{d_{2}}},
$$

where $\alpha$ - heat-transfer coefficient, $\mathrm{W} /\left(\mathrm{m}^{2} \cdot \mathrm{K}\right) ; \lambda_{s}$ - heat conductivity coefficient of material of VGHT unit's pipe, $\mathrm{W} /(\mathrm{m} \cdot \mathrm{K}) ; \lambda_{z}$ - heat conductivity coefficient of borehole filler layer, $\mathrm{W} /(\mathrm{m} \cdot \mathrm{K}) ; d_{1}$ - inner diameter of VGHT unit's pipe, $\mathrm{m} ; d_{2}-$ outer diameter of VGHT unit's pipe, $\mathrm{m} ; \delta_{z}$ - borehole filler layer thickness, $\mathrm{m}$.

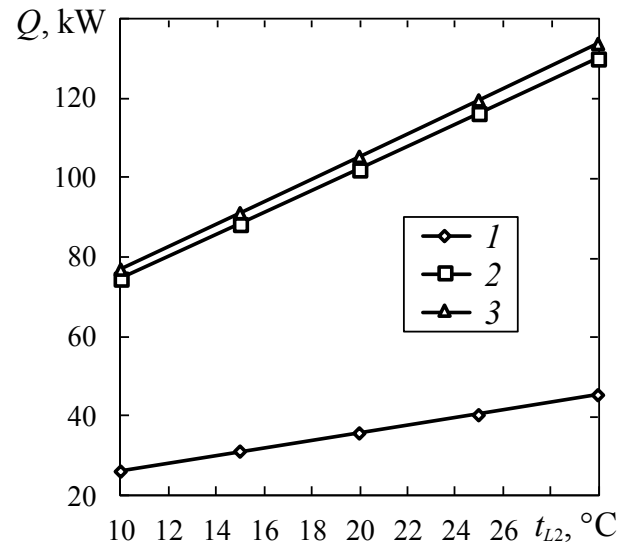

Fig. 2. Heat flow change, removed into VGHT units, depending on the water temperature at outlet from VGHT units for pipes, made of various materials: 1 - polyethylene $\left(\lambda_{s}=0.38\right.$ $\mathrm{W} /(\mathrm{m} \cdot \mathrm{K})) ; 2$ - stainless steel AISI $321\left(\lambda_{s}=17.5\right.$ $\mathrm{W} /(\mathrm{m} \cdot \mathrm{K})), 3$ - cast iron BS200 $\left(\lambda_{s}=54.0\right.$ $\mathrm{W} /(\mathrm{m} \cdot \mathrm{K}))$.

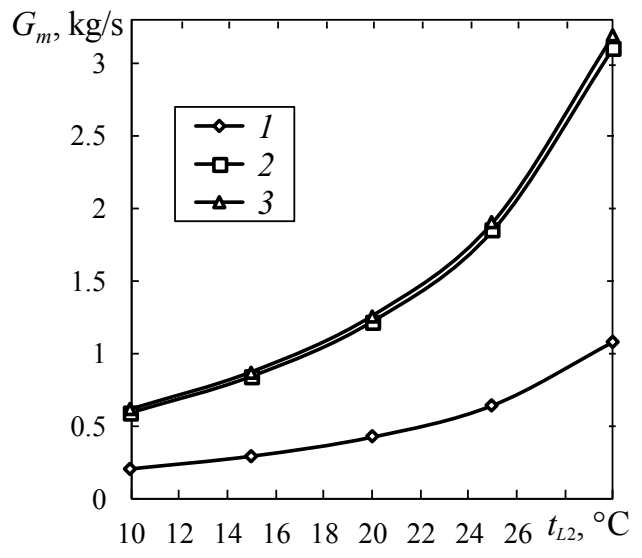

Fig. 3. Mass flow rate change of cooled water, depending on its temperature at outlet from VGHT units for pipes, made of various materials: 1 - polyethylene $\left(\lambda_{s}=0.38 \mathrm{~W} /(\mathrm{m} \cdot \mathrm{K})\right) ; 2$ stainless steel AISI $321\left(\lambda_{s}=17.5 \mathrm{~W} /(\mathrm{m} \cdot \mathrm{K})\right), 3-$ cast iron BS200 $\left(\lambda_{s}=54.0 \mathrm{~W} /(\mathrm{m} \cdot \mathrm{K})\right)$.

The heat transfer coefficient of water, flowing around the straight pipes, can be determined by equations in work [6]. U-shaped steel pipes with a diameter of $32 \times 3.0 \mathrm{~mm}$ have been taken as VGHT units. The heat conductivity of pipes has been taken equal to $17.5 \mathrm{~W} /(\mathrm{m} \cdot \mathrm{K})$. Pipes are located in the borehole with a diameter of $120 \mathrm{~mm}$. Material heat conductivity of filler layer of borehole is $2.3 \mathrm{~W} /(\mathrm{m} \cdot \mathrm{K})$. Design calculation of VGHT units has been carried out considering the possibility of additional heat removal from the oilimmersed transformer, equal to $100 \mathrm{~kW}$. Meanwhile, ground design temperature was $8^{\circ} \mathrm{C}$, while temperatures of heat-transfer agent at inlet of and at outlet from VGHT units were $40^{\circ} \mathrm{C}$ and $20^{\circ} \mathrm{C}$ respectively. Under given conditions, the estimated total length of VGHT units was $213.2 \mathrm{~m}$. In this regard, when carrying out research calculations, length of VGHT units (depth of a borehole) was $40 \mathrm{~m}$, quantity -3 . The estimated calculations have been carried out for pipes, made of polyethylene, stainless steel and cast iron. The temperature difference of heat-transfer agent at inlet of and at outlet from VGHT unit has been varied 
from $10^{\circ} \mathrm{C}$ to $30^{\circ} \mathrm{C}$. The water temperature at inlet of VGHT unit has been taken constant $\left(t_{L 1}=40^{\circ} \mathrm{C}\right)$. Ground design temperature was $10^{\circ} \mathrm{C}$.

The results of numerical studies show that heat flow magnitude, additionally removed from power transformer, depends essentially on temperature characteristics of heat-transfer agent and material of U-shaped pipes of VGHT units at the same dimensions.

In Fig. 2 we may see that substitution of polyethylene pipes by steel pipes increases the heat flow by 2.84-2.87 times under the studied operating con-ditions of VGHT units. Increase of heat amount, transferred into VGHT units, leads to an increase of mass flow rate of the cooled agent (Fig. 3). It should be noted that further increase of heat conductivity coefficient of pipes` walls of VGHT units, for example by 3.086 times, leads to the heat flow increase only by $2.86-2.89 \%$. In this case, the main heat transfer resistance is concentrated in the filler layer of borehole and heat transfer resistance contribution of this layer to the total heat transfer resistance reaches up to $97.1 \%$.

\section{Conclusion}

Performed numerical studies show that in order to increase the heat flow, additionally removed from power transformer, we should choose VGHT unit's steel pipes and thickness of filler layer of borehole should be minimal. Thus, it can be said that application of the proposed liquid cooling system of oil-immersed transformers will let additionally remove up to $50 \%$ of heat at the moments of peak heat loads.

The work was performed with funding from the grant of the President of the Russian Federation No. MK-5215.2016.8 (contract No. 14.Z56.16.5215-MK dated March 14, 2016).

\section{References}

1. L. Kish, Heating and cooling of transformers (Energy, Moscow, 1980) [in Russian]

2. A.M. Golunov, N.S. Seshenko, Cooling devices of oil-immersed transformers (Energy, Moscow, 1976) [in Russian]

3. A.V. Dmitriev, O.S. Dmitrieva, I.N. Madyshev, MATEC Web of Conferences, 95, 15008 (2017), DOI: 10.1051/matecconf/20179515008

4. O.S. Dmitrieva, G.R. Patrakova, A.V. Dmitriev, 2017 International Conference on Industrial Engineering, Applications and Manufacturing (ICIEAM), 1-4, (2017), DOI: 10.1109/ICIEAM.2017.8076305

5. S.O. Filatov, V.I. Volodin, Proceedings of BSTU. Chem. and tech. of inorganic substances, 3, 179 (2011) [in Russian]

6. K. Savina, A. Abramovskih, V. Haymin, S. Lavrinenko, MATEC Web of Conferences, 72, 01042 (2016), DOI: 10.1051/matecconf/20167201042 